University of South Florida

DIGITAL COMMONS

Digital Commons @ University of

@ UNIVERSITY OF SOUTH FLORIDA

South Florida

4-1-1999

\title{
Particle Trajectories in an Indian Ocean Model and Sensitivity to Seasonal Forcing
}

\author{
Meredith A. Haines \\ University of South Florida \\ Rana A. Fine \\ University of Miami \\ Mark E. Luther \\ University of South Florida, mluther@usf.edu \\ Zaihua Ji \\ University of South Florida
}

Follow this and additional works at: https://digitalcommons.usf.edu/msc_facpub

Part of the Marine Biology Commons

\section{Scholar Commons Citation}

Haines, Meredith A.; Fine, Rana A.; Luther, Mark E.; and Ji, Zaihua, "Particle Trajectories in an Indian Ocean Model and Sensitivity to Seasonal Forcing" (1999). Marine Science Faculty Publications. 42.

https://digitalcommons.usf.edu/msc_facpub/42

This Article is brought to you for free and open access by the College of Marine Science at Digital Commons @ University of South Florida. It has been accepted for inclusion in Marine Science Faculty Publications by an authorized administrator of Digital Commons @ University of South Florida. For more information, please contact digitalcommons@usf.edu. 


\title{
Particle Trajectories in an Indian Ocean Model and Sensitivity to Seasonal Forcing
}

\author{
Meredith A. Haines \\ Department of Marine Science, University of South Florida, St. Petersburg, Florida \\ RANA A. FINE \\ Rosenstiel School of Marine and Atmospheric Science, University of Miami, Miami, Florida \\ MARK E. Luther AND ZAiHuA Ji \\ Department of Marine Science, University of South Florida, St. Petersburg, Florida
}

(Manuscript received 12 August 1996, in final form 18 May 1998)

\begin{abstract}
Trajectory experiments in a thermocline layer of an Indian Ocean model are used to investigate the role of different meridional transport mechanisms and quantify spreading pathways and rates under different forcing. Particles are introduced along two boundaries: the south Indian Ocean at $30^{\circ} \mathrm{S}$ and the Indonesian Throughflow. Particles are advected horizontally within the layer by archived model velocity fields $\left(1 / 3^{\circ} \times 13^{\circ}\right.$ resolution) for a period of 50 years. The velocity fields are the result of forcing the model by monthly mean climatology (case A). The distribution of particles within the Tropics suggests efficient water mass blending; model results show a mixture of three parts South Indian Central Water to one part Indonesian Throughflow. In agreement with chlorofluorocarbon (CFC) observations, transport of thermocline waters along the western boundary into the northern Indian Ocean occurs on timescales of less than two decades. Additional Lagrangian experiments carried out with the seasonality removed from the velocity fields directly (taking the mean in case B) and from the forcing (case C) allow the role of horizontal eddy transport to be evaluated. Significant northward transport of southern subtropical gyre waters along the western boundary does not occur unless there is eddy transport, even though the mean flow appears to dominate the cross-equatorial transport in the immediate vicinity of the equator. Particles reach northward of $10^{\circ} \mathrm{N}$ on shorter timescales $(<20 \mathrm{yr})$ in case A compared with case $\mathrm{C}(>20 \mathrm{yr})$. Both the mean and seasonal forcing components are important for the meridional flux of particles. The results suggest that to adequately simulate meridional transport of mass and water mass properties in the Indian Ocean, models should include the full annual cycle. In a new methodology, CFC-11 concentrations along trajectories are calculated using observed CFC-11 concentrations for boundary conditions. Additional CFC observations allow model-data comparisons to be made in the interior of the domain. The method may be useful in other studies of transport rates and processes where both computing power and good quality high-resolution observations are available.
\end{abstract}

\section{Introduction}

It is well documented that the atmospheric forcing of the Indian Ocean is dominated by the annually reversing monsoon winds (see Knox 1987). These winds drive reversals in the western boundary currents off the east coasts of Africa and India and in the equatorial region (Fig. 1). The seasonal cycle is asymmetric, with the southwest monsoon winds and the Somali Current being much more energetic than those of the northeast monsoon. Large amplitude eddy variability is found in the

Corresponding author address: Meredith A. Haines, Department of Marine Science, University of South Florida, 140 7th Ave S., St. Petersburg, FL 33701.

E-mail: meredith@marine.usf.edu western boundary currents and along the equator, associated with nonlinearly interacting equatorial waves. The eddy transport of heat and of chemical tracers by the chaotic eddy field and by the regularly reversing boundary currents is likely to influence the transport and renewal of water mass properties in the Indian Ocean.

Tracer and hydrographic studies support the suggestion by Warren et al. (1966) and Swallow (1984) that the Arabian Sea thermocline may be renewed (ventilated) by Southern Hemisphere water. Using CFC and hydrographic data Prunier (1992) finds the effects of the Marginal Seas (Red Sea and Persian Gulf waters) are most pronounced north of the zero wind stress curl $\left(12^{\circ} \mathrm{N}\right)$ in the Arabian Sea. South of $12^{\circ} \mathrm{N}$, in the Somali Basin, she finds elevated concentrations of CFCs have reached across the equator from the Southern Hemi- 

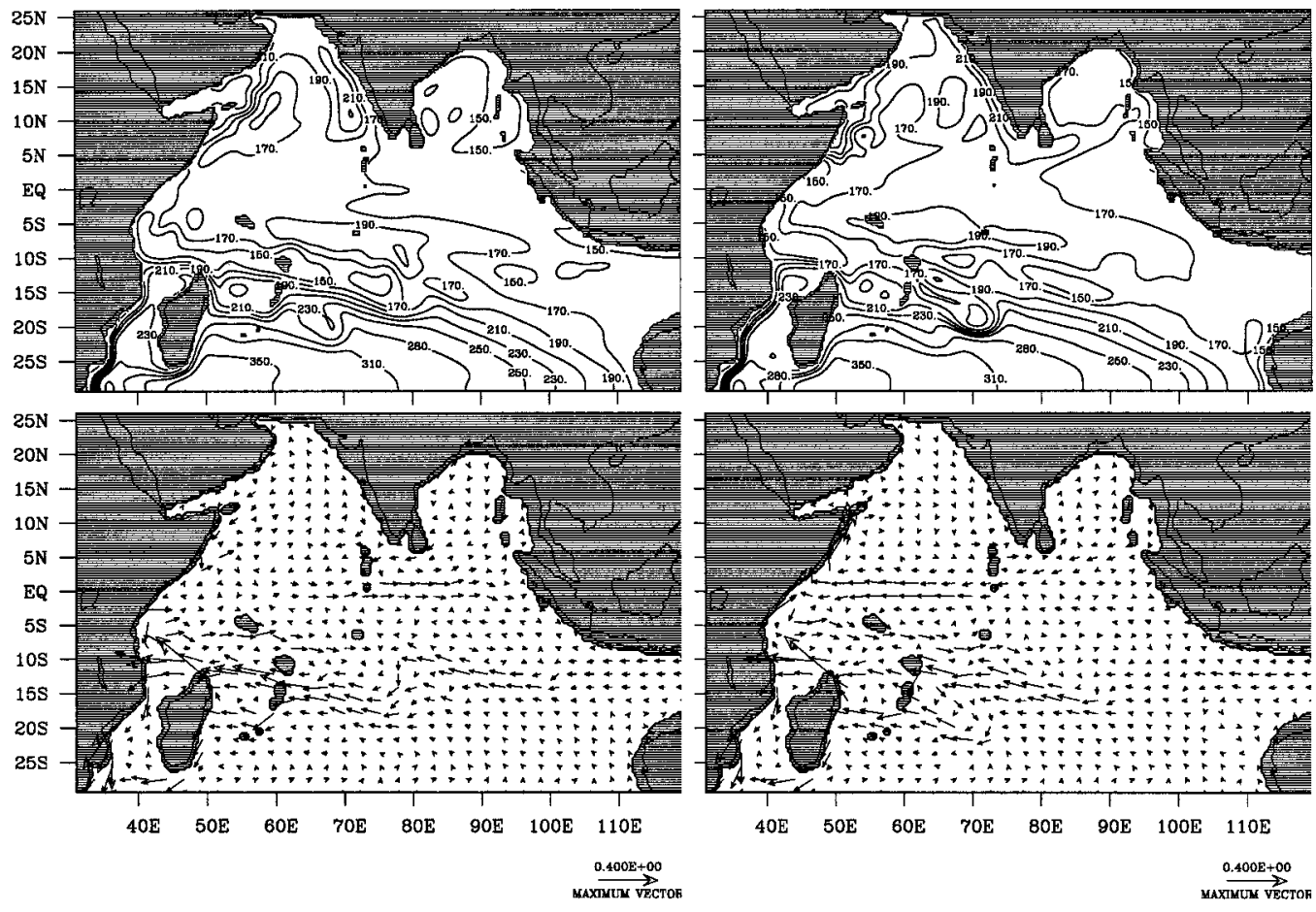

FIG. 1. The Indian Ocean model domain showing midthermocline layer thickness $(\mathrm{m})$ and velocity vectors $\left(\mathrm{m} \mathrm{s}^{-1}\right)$ in January (left) and July (right). These patterns are typical for the northeast monsoon (boreal winter) and southwest monsoon (boreal summer), respectively. Areas shallower than $200 \mathrm{~m}$ appear as land.

sphere oxygen maximum waters and Antarctic Intermediate Water. In the analysis of an annual-mean hydrographic dataset, You and Tomczak (1993) establish South Indian Central Water (SICW) and the Indonesian Throughflow (IT) as the two sources for thermocline ventilation of the northern Indian Ocean, with small contributions from the Marginal Seas. The ventilated waters (Fine 1993) most likely contributing to SICW $\left(T=25^{\circ}-8^{\circ} \mathrm{C}, S=35.8^{\circ}-34.6 \mathrm{psu}\right)$ originate in the austral wintertime south of the subtropical convergence (McCartney 1982; Sprintall and Tomczak 1993).

Studies show that to get the water mass ventilation correct, eddy-resolving models are required. Parameterizations of eddy processes in coarse resolution models cannot produce a transport consistent with that of a highresolution model that explicitly resolves the eddy processes (Figueroa 1994). The CFCs have been used to assess subgrid-scale mixing schemes in global ocean models (England 1995; Robitaille and Weaver 1995). The results clearly point out that ventilation is overestimated in coarse-scale isopycnal models.

Here we perform particle trajectory experiments using velocity fields from an eddy-resolving layer model. The aims are 1) to examine the pathways and timescales of spreading of thermocline waters entering the Indian Ocean at the southern and eastern open boundaries, 2) to evaluate the role of horizontal eddy transports on the meridional circulation of the Indian Ocean, and 3) to assess model behavior. Additionally, using CFC obser- vations as boundary conditions, the relative contributions of CFCs from the IT and the southern subtropical gyre to the northern Indian Ocean are modeled and evaluated.

In the following sections, firstly the circulation model is described and model mass transports are compared to observations. This provides both a more detailed review of the circulation of the Indian Ocean, and an understanding of both the limitations of the physical model and of the observations (in the decade prior to the World Ocean Circulation Experiment) in this highly variable ocean. Subsequently the Lagrangian particle experiments are described. CFC concentrations along particle trajectories are then calculated and the distributions compared to CFC observations. The results also bring to the fore certain aspects of model behavior. Finally, additional Lagrangian experiments are used to examine the effect of seasonal forcing and the resultant eddies on the meridional transport.

\section{Indian Ocean model}

\section{a. Description and circulation comparison to observations}

The circulation model covers the Indian Ocean basin to $30^{\circ} \mathrm{S}$ (Fig. 1) on a $1 / 12{ }^{\circ}$ staggered grid $\left(1 / 6^{\circ}\right.$ between like variables). The layer model evolved from Luther and O'Brien's (1985) [as enhanced by Jensen (1991, 
1993) to include additional layers and recoded by $\mathrm{J}$. Capella]. More recently, Ji and Luther (1998, manuscript submitted to J. Geophys. Res.) embedded mixed layer dynamics in the uppermost model layer. Horizontal mixing is accomplished in the model by eddy processes, that are largely resolved by the fine grid, and by eddy viscosity parameterization of the subgrid-scale processes.

The 200-m isobath is used as the solid wall boundary between ocean and land or islands. There are open boundaries in the south, corresponding to the center of the south Indian subtropical gyre, and in the east downstream of the IT. The purely dynamical version of the circulation model is currently run in near real-time with observed monthly averaged winds, and the model output are available via the Internet [kelvin.marine.usf.edu: pub/ndnocn (anon. ftp); http://ompl.marine.usf.edu].

The model has four layers with a surface mixed layer embedded in the first layer. The reduced gravity approximation is applied so that the horizontal pressure gradient vanishes in the deepest layer (Gill 1982); that is, it is at rest. The second layer spans the midthermocline and the third layer corresponds to the lower thermocline. Initial model conditions are chosen according to field observations (Wyrtki 1971; Gent et al. 1983 ) with a first-layer thickness of $80 \mathrm{~m}$, second-layer thickness of $250 \mathrm{~m}$, and a third-layer thickness of 500 $\mathrm{m}$. These thicknesses vary geographically and temporally. A Sommerfeld radiation condition (Camerlengo and O'Brien 1980) is applied at the open boundaries as in Jensen (1991).

The open boundary condition allows mass to pass through the boundary as required by the interior solution while allowing wave energy generated in the interior to pass out of the model domain without reflection. In addition, transport through the southern open boundary is adjusted so that mass in the basin is conserved over a 1-yr timescale. Temperature of incoming water is specified according to climatology. After about $10 \mathrm{yr}$ of spinup, the model settles into a steady annual cycle.

Velocities, calculated from transports and layer thicknesses, are archived as 6-day averages at a lower resolution of $1 / 3^{\circ}$ by subsampling. Velocities in the midthermocline layer of the model are shown in Fig. 1, which depicts the winter and summer monsoon seasons and illustrates the current reversals. The largest velocities, up to $1 \mathrm{~m} \mathrm{~s}^{-1}$, are found in the western boundary.

The model reproduces the major current systems of the Indian Ocean. The westward flowing South Equatorial Current (SEC) at $10^{\circ}-15^{\circ} \mathrm{S}$ bifurcates at the coast of Madagascar (Schott et al. 1990; Woodberry et al. 1989). The northward branch flows around the tip of Madagascar and along the African Coast as the East African Coastal Current (EACC), which meets the seasonally reversing Somali Current. During the northeast monsoon, these waters flow eastward along $3^{\circ} \mathrm{S}$ in the South Equatorial Counter Current (SECC), but during the southwest monsoon, the EACC joins the now north- ward flowing Somali Current. Eddy activity is also highest in the west, particularly during the southwest monsoon. Between Kenya and Socotra, two strong clockwise eddies spin up in the model Somali Current system, simulating the observed two-gyre system (Findlay 1866; Bruce 1973; Swallow and Fieux 1982; Luther 1999).

\section{b. Model transports as compared to observations}

Model transports agree well with long timescale, depth-averaged observations at the IT, and not as well with observations near the southern open boundary. The relative contributions of southern subtropical gyre waters to the model interior may be underestimated because the southern model boundary cuts through the middle of the gyre. This has the effect of weakening the gyre circulation, even though the net flow across the southern open boundary is forced to meet mass balance with the IT inflow. Similarly, while in agreement in the mean, the model underestimates the annual range for IT, probably because there is no forcing included from the Pacific. It is typical for the deeper layers of a wind-driven model to have weak flows (Semtner and Chervin 1992). In addition, some model sluggishness is likely due to the climatological averaging of the forcing. Details of the model transports and observations are described below.

Meyers et al.'s (1995) calculations offer the first climatology for the IT, whereas earlier observations have highlighted the energetic variability of the region on short and interannual timescales. Over a 6-yr period they find an annual mean of $11 \mathrm{~Sv}\left(\mathrm{~Sv} \equiv 10^{6} \mathrm{~m}^{3} \mathrm{~s}^{-1}\right)$ westward (6 Sv due to the reference layer flow). A maximum of $18 \mathrm{~Sv}$ occurs in August-September and a minimum of $6 \mathrm{~Sv}$ occurs in May-June and again in OctoberNovember. Hydrographic sections sampled during opposite phases of ENSO (Fieux et al. 1994, 1996) have indicated throughflows from a high of $18 \pm 7 \mathrm{~Sv}$ westward in boreal summer to $2.6 \pm 9 \mathrm{~Sv}$ eastward in boreal winter.

Compared to observations of a mean flow of $11 \mathrm{~Sv}$ and an annual range of $12 \mathrm{~Sv}$, the model IT transports have a comparable mean flow, $12.5 \mathrm{~Sv}$, and a smaller annual range, $8.5 \mathrm{~Sv}$ in the spring to $16 \mathrm{~Sv}$ in the summer. Eighty percent of the total transport is in the upper two model layers, consistent with observations (e.g., Fieux et al. 1994, 1996).

Some particle trajectories (described in later sections) are seen to first approach the IT region and then turn westward, suggesting that the eastern gyral current is represented in the model. A fairly strong eastward current seen fleetingly in the northern end of the IT opening may be related to the South Java Current (SJC), but it only appears in the deepest layer, and not quite in phase with SJC observations. Quadfasel and Cresswell (1992) suggest the SJC is excited by the arrival of remotely forced equatorial Kelvin waves. Whereas equatorial Kelvin waves do appear in the model, detailed features 
of the SJC and the Leeuwin Current are likely to be sensitive to the inclusion of Pacific and local forcing, including buoyancy, that is not considered in the model formulation.

Along most of the southern boundary the model transport is small and positive (i.e., into the model domain) and the model shows a large outflow in the west. The net flow at the southern boundary is out of the model domain and the combined magnitude of the outflow in all three layers is relaxed to match the net inflow through the Indonesian Archipelago (Ji and Luther 1998, manuscript submitted to J. Geophys. Res.). The flux correction, necessary for mass balance, is applied in proportion to the velocities along the length of the southern boundary, and consequently is concentrated in the west. The seasonal maximum and minimum are out of phase with the IT flow, and of smaller amplitude-ranging from $11 \mathrm{~Sv}$ in late summer to $14.5 \mathrm{~Sv}$ in the spring. Based on hydrographic observations and a silica budget, Toole and Warren (1993) calculate a net transport across $32^{\circ} \mathrm{S}$ of $7 \pm 10 \mathrm{~Sv}$ westward, but Robbins and Toole (1997), in a reanalysis of the same data, calculate a reduced meridional circulation even though they suggest a similar value for the net flow across the section.

Swallow et al. (1988) review transports at two sites near Madagascar and the depth distribution of these observed transports are now compared to the model. Off Cape Amber, northeast Madagascar, the total transports between 0 and $1100 \mathrm{~m}$ calculated by geostrophy (28 $8 \mathrm{~Sv})$ and current meter time series (27 $\pm 9 \mathrm{~Sv})$ agree well with the net annual average transport calculated for this section from the model (24 Sv northwestward). Over $80 \%$ of the model transport occurs in the top two layers, with the remaining $4 \mathrm{~Sv}$ in the third model layer. The observed $10 \mathrm{~Sv}$ that occurs in the depth range 200$700 \mathrm{~m}$, corresponding to model layer 3 (260-700 m), is two and one-half times greater than the model, but still comparable to the total uncertainty in the observed transport. Off southeast Madagascar, the integrated-to700-meters transport estimates from geostrophy and current meter time series are on the order of $20 \mathrm{~Sv}$ southwestward. Model transports are significantly lower, totaling only $7 \mathrm{~Sv}$ for all three layers.

While Lagrangian particle experiments were carried out in both model layers 2 and 3, only layer 2 experiments will be described. The mass transport comparisons suggest that the layer 3 velocities are underestimated, even while the depth-integrated transports are reasonable within the large uncertainties. Results of CFC modeling on layer 3 (not described) further confirm that the layer 3 velocities are sluggish.

\section{Lagrangian experiments}

The intent of the trajectory experiments is to examine the horizontal water mass spreading pathways and timescales within the thermocline from the two open boundaries. Experiments introduce particles at $1 / 12^{\circ}$ intervals
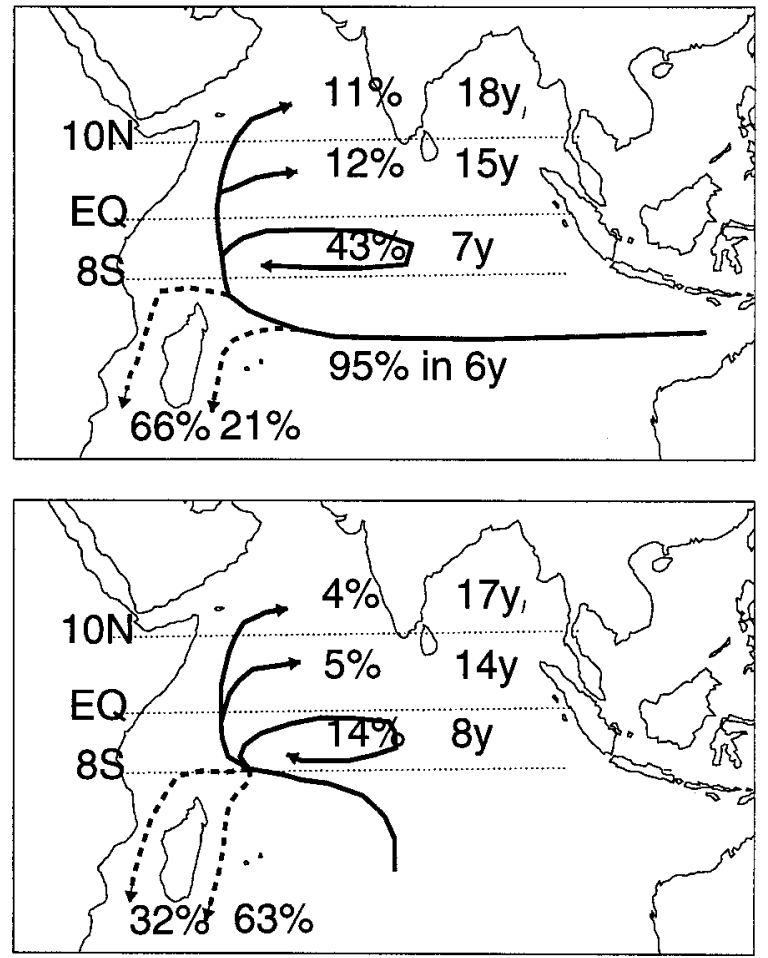

FIG. 2. Summary of 50-yr-long trajectory paths as produced from monthly forced climatology, for particles introduced at $1 / 12^{\circ}$ intervals along the open boundaries in midthermocline layer 2 from the (a) east and (b) south. The percentage of particles that reach the marked latitudes, and the average time taken, is indicated. For example, in (a) $43 \%$ of the particles cross north of $8^{\circ} \mathrm{S}$ in an average 6 years, but only $12 \%$ go further, to the equator, and $11 \%$ reach northward as far as $10^{\circ} \mathrm{N}$ (in $18 \mathrm{yr}$ on average). The percentage remaining in the model domain after 50 years is the shortfall from $100 \%$ in the sum of those shown exiting in the southwest corner of the model domain; that is, (a) $13 \%$ and (b) $5 \%$.

along $30^{\circ} \mathrm{S}$ in the south Indian Ocean and along $119^{\circ} \mathrm{E}$ corresponding to the IT. Trajectories are generated by advecting the particles using archived horizontal velocities. Although vertical mass exchange occurs in the circulation model between the mixed layer and first and second layers, as demanded by the forcing, the simplification is made that particles are trapped in the layer.

In a series of 12 experiments particles are initialized in the middle of each month in turn. Trajectories are calculated by integrating the velocities using a fourthorder Runge-Kutta scheme with adaptive step-size control (Press et al. 1992). At each time step linearly interpolated velocities are integrated to give the distance each particle moves with an accuracy requirement set at 5 parts in $10^{6}$. The average time step is 30 minutes and locations are recorded every 30 days. The velocities are forced by monthly atmospheric climatology (Rao et al. 1989). An annual cycle of velocities is applied repeatedly for 50 years, corresponding to the timescale of the CFC transient.

Figure 2 summarizes the main pathways and time- 
scales of the particle trajectories. Details are discussed in the following sections. Note that it was found that the percentages and timescales did not vary significantly between an average taken over the more intensive set of monthly experiments and an average over only onequarter of the trajectories (representing each season). For example, the fraction of particles reaching north of $10^{\circ} \mathrm{N}$ differed by less than $2 \%$ and less than 2 years. This gives some confidence that the number of particles used is adequate.

\section{a. Eastern boundary}

Particle progress from the eastern boundary over successive 5-yr periods is illustrated in Fig. 3. An average of 97 particles enter the model domain between $9^{\circ} \mathrm{S}$ and $17^{\circ} \mathrm{S}$ at longitude $119^{\circ} \mathrm{E}$. The remainder $(9 \%)$ have initial velocities that do not carry them into the model domain. Particles traverse the model domain from east to west (to longitude $45^{\circ} \mathrm{E}$ ) in an average of six years, and are then carried north and south along the western boundary. Although $43 \%$ of the particles reach north of $8^{\circ} \mathrm{S}$, they only do so in the western boundary. Many of those that reach $8^{\circ} \mathrm{S}$ do not reach farther north because they are swept back eastward along $5^{\circ} \mathrm{S}$. Particles are also carried southward along the east coast of Madagascar; $21 \%$ escape the model domain by this route. After 50 years, $87 \%$ of the particles have exited in the southwest corner of the model domain. The location of the remaining 13\% is not apparent in Fig. 2, however, because even particles that reach the Arabian Sea (11\% after an average $18 \mathrm{yr}$ ) may be swept out of the domain over the 50-yr period. However, by looking at the trajectory sequences (Fig. 3), the location of those remaining particles can be seen. There are some particles in the Arabian Sea (nominally north of $10^{\circ} \mathrm{N}$ ) and some in the tropical band where the particles appear to flow east and west with the seasonally reversing zonal equatorial currents.

\section{b. Southern boundary}

An average of 693 particles enter the model domain along $30^{\circ} \mathrm{S}$ between $31^{\circ} \mathrm{E}$ and $119^{\circ} \mathrm{E}$. The remainder (30\%) have initial trajectories that do not carry them into the model domain. The subtropical gyre circulation is apparent in the northwestward trend in the trajectories (Fig. 4), as well as in the large percentage that exits the domain south of Madagascar (63\%). The gyre interior is particle free after a short time period $(6 \mathrm{yr})$ because once particles exit the domain, they cannot return (see discussion).

A smaller percentage of particles reach $8^{\circ} \mathrm{S}$ from the southern boundary $(14 \%)$ than the eastern boundary and the average timescale is comparable ( $8 \mathrm{yr})$. Only $4 \%$ reach as far north as $10^{\circ} \mathrm{N}$ after about 17 years (Fig. 2b). Those reaching the northern Arabian Sea appear to circulate in the gyre confined north of the zero wind stress curl. A large percentage of the particles remaining in the model domain are in the Tropics, which is similar to the fate of particles from the east. These appear to be separated into three bands: north, south, and on the equator. Along the northern and equatorial bands, particles do not get farther eastward than the central Indian Ocean.

\section{c. Age and tracer maps}

To compare model-derived concentrations with observations, first interior ages are calculated using particle trajectories, and then interior CFC concentrations are calculated using a new methodology in which observations at model boundaries are combined with particle trajectory ages. The trajectory experiments give the positions of particles over a 50-yr-long period. The trajectories also map in space the relative age of water masses, assuming that particles follow the same trajectory if they enter at the same time in the annual cycle.

To calculate interior ages from particle trajectories, first, trajectories are linearly interpolated to a finer resolution of 8 days from the original 30 days. The interpolation improves the age calculation for those regions through which particles move rapidly. The particle ages from four experiments (a subset representing each season from the original 12 months) are then averaged into $1 / 3^{\circ}$ by $1 / 3^{\circ}$ bins.

A map of particle-derived ages shows that no particles have yet reached the Bay of Bengal (Fig. 5). The experiments suggest that the Bay of Bengal midthermocline waters are at least $50 \mathrm{yr}$ older than thermocline waters at the model boundaries. This is consistent with You and Tomczak (1993, hereinafter YT93), who find the oldest central waters in the Bay of Bengal, which they refer to as "aged SICW." The oldest particles are found at the northeastern limits of the Arabian Sea. Particles take on average 20-50 yr to reach the northern Arabian Sea from either boundary, although some particles do reach this area within 10-15 yr (Figs. 3 and 4). The center of the gyre in the northern Arabian Sea remains relatively particle free. Particles reach the equatorial region in 10-20 yr from either boundary. Particles reach all of the south Indian subtropical gyre in less than 10 years from either boundary. However, there is also a pocket of older particles in the low velocity region between Madagascar and the African coast.

To calculate model interior CFC-11 concentrations, CFC-11 observations are used at the critical locations corresponding to the model boundaries. Based on Charles Darwin CFC-11 data collected in NovemberDecember 1987 along $32^{\circ} \mathrm{S}$ (Fine 1993; Toole and Warren 1993) water at layer 2 depths is at $85 \%$ saturation relative to the contemporary 1987 atmosphere, with no significant zonal variation in saturation. Therefore, based on the Southern Hemisphere atmospheric time history (Walker et al. 1996, personal communication), these waters would have been in saturation equilibrium 


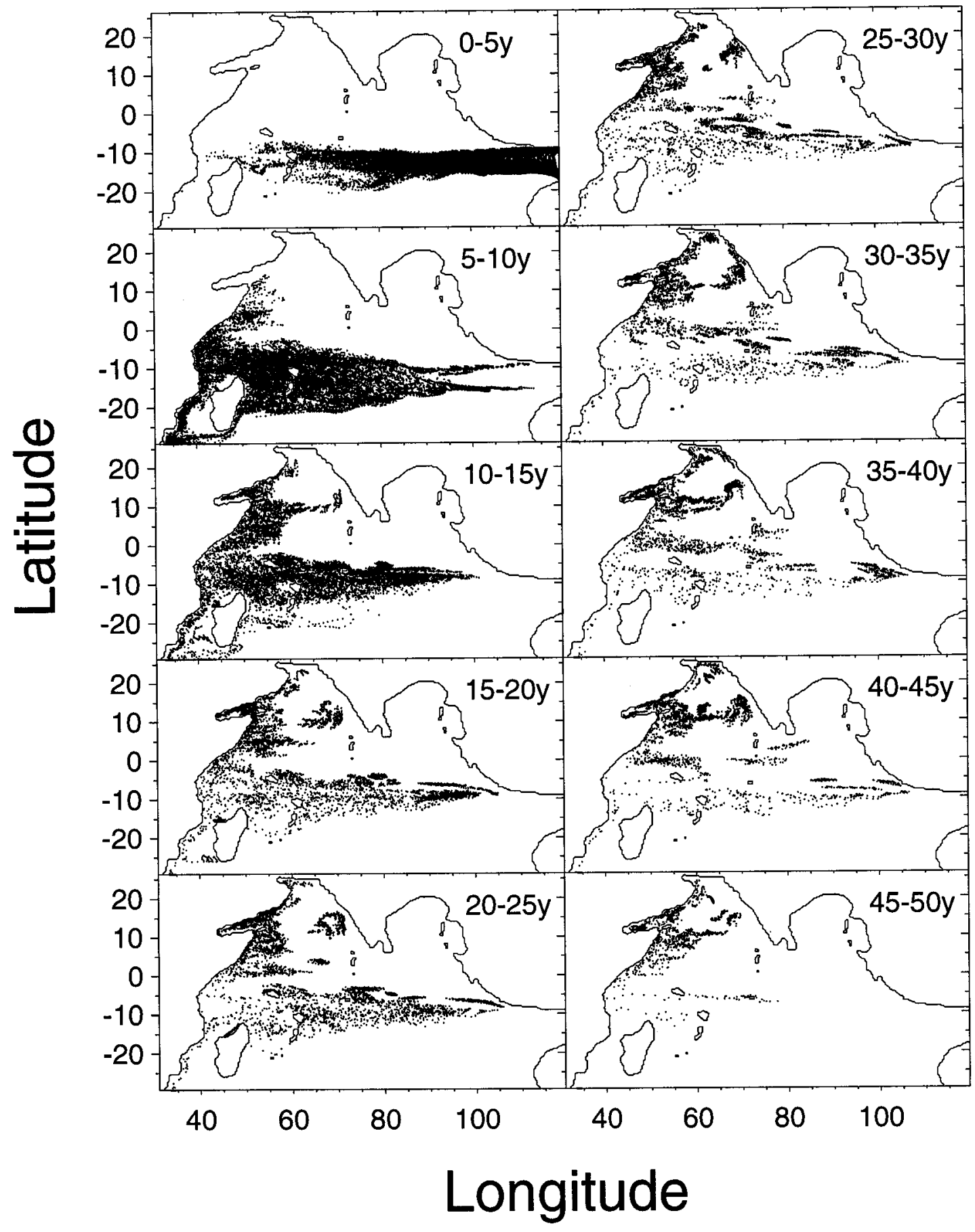

FIG. 3. The progression of Lagrangian particles from their entry points along the eastern boundary in model layer 2. Position is marked as a point every 30 days in 5-yr intervals. The patterns are similar for particles introduced in each month in the annual cycle and a composite of four seasonal initializations are shown.

with the 1983 atmosphere. However, there is considerable uncertainty in the degree to which a water mass reaches equilibrium at the source region and how it varies in time. For example, in newly formed Labrador Sea Water Wallace and Lazier (1988) found saturations of $60 \%$, whereas in Greenland Sea surface water Rhein
(1991) found saturations of 79\%. Model exercises by England et al. (1994) suggest about $10 \%$ or more undersaturation in subantarctic mode water. The observed saturation level of $85 \%$ along the $32^{\circ} \mathrm{S}$ section may well be close to the limit that these waters reach. For saturation conditions from $85 \%$ to $100 \%$ at the time 


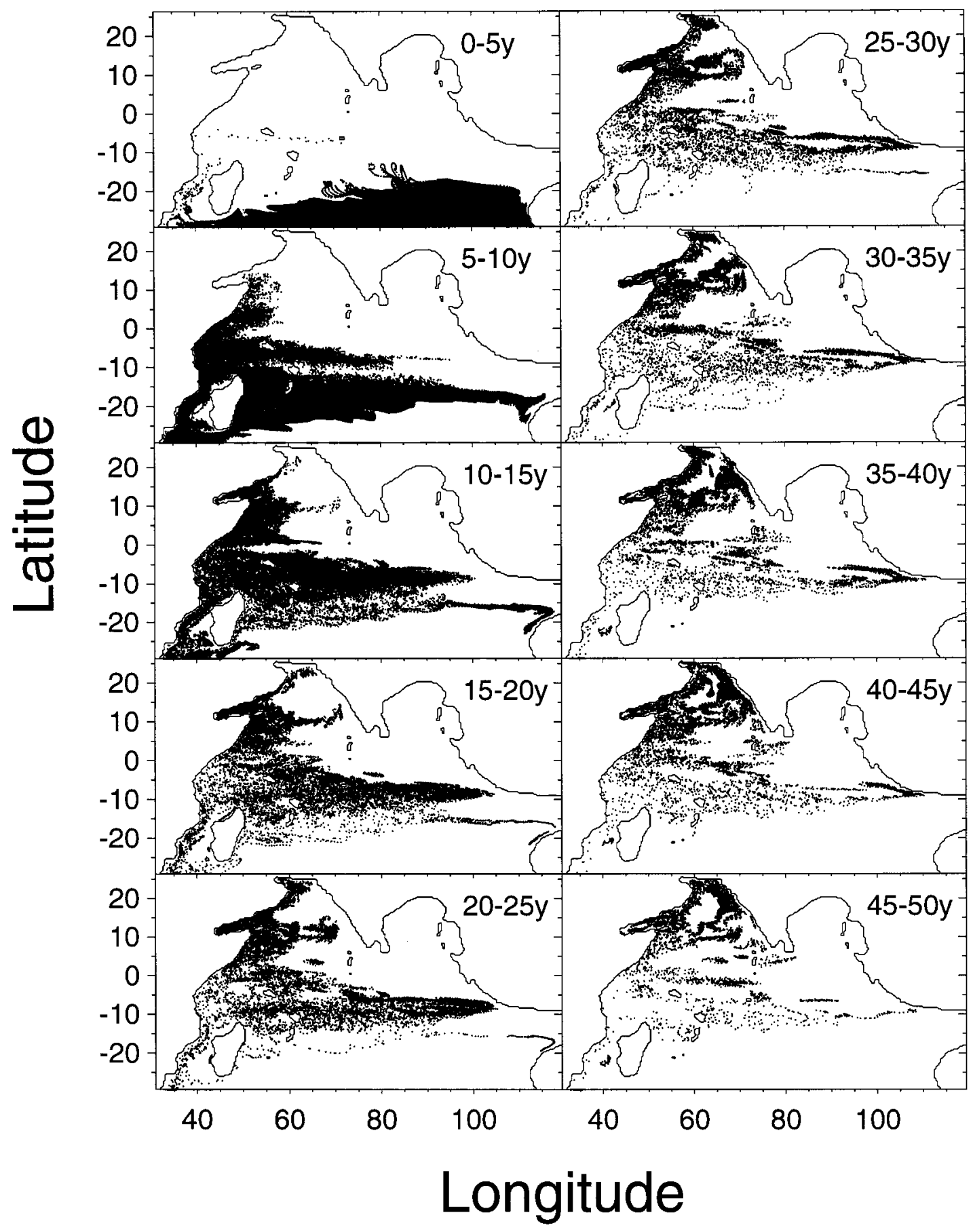

FIG. 4. The progression of Lagrangian particles from their entry points along the southern boundary in model layer 2. Position is marked as a point every 30 days in 5 -yr intervals. The composite of four seasonal initializations are shown.

of formation, the estimated pCFC age is between 0 and $4 \mathrm{yr}$.

A CFC-11 distribution of southern source waters is constructed for 1987 by assigning a CFC concentration at each interior grid point based on the relative particle age (Fig. 5) plus the ventilation partial pressure age (e.g., Fine et al. 1988; Doney and Bullister 1992) of waters at the boundary. The main caveat is that effects of mixing on the pCFC age are not taken into account; these effects will be most pronounced in high gradient regions (e.g., Doney et al. 1997). It is also assumed that temperature and pCFC age are steady with time. Two cases for the ventilation age of layer 2 waters are considered: $0 \mathrm{yr}$ at $85 \%$ saturation, and $4 \mathrm{yr}$ at $100 \%$ sat- 


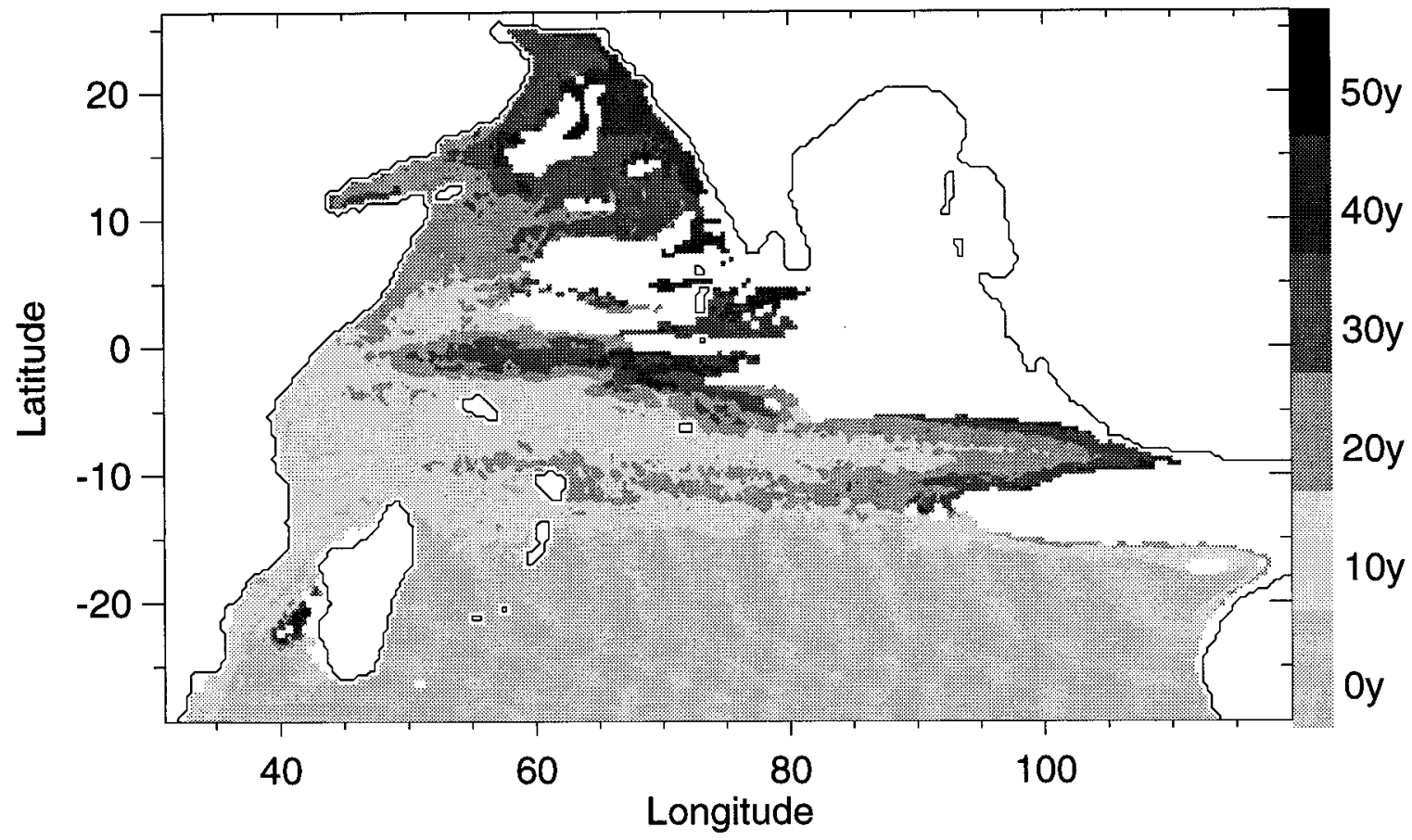

FIG. 5. Particle trajectory age (in years) of waters entering layer 2 along the southern boundary (relative to zero on boundary).

uration. (Note the measured concentration is consistent with either interpretation.) The atmospheric time history (Walker et al. 1996, personal communication), model water temperature, and Levitus (1982) salinity are then used in solubility (Warner and Weiss 1985) calculations to produce model interior CFC-11 concentrations. For

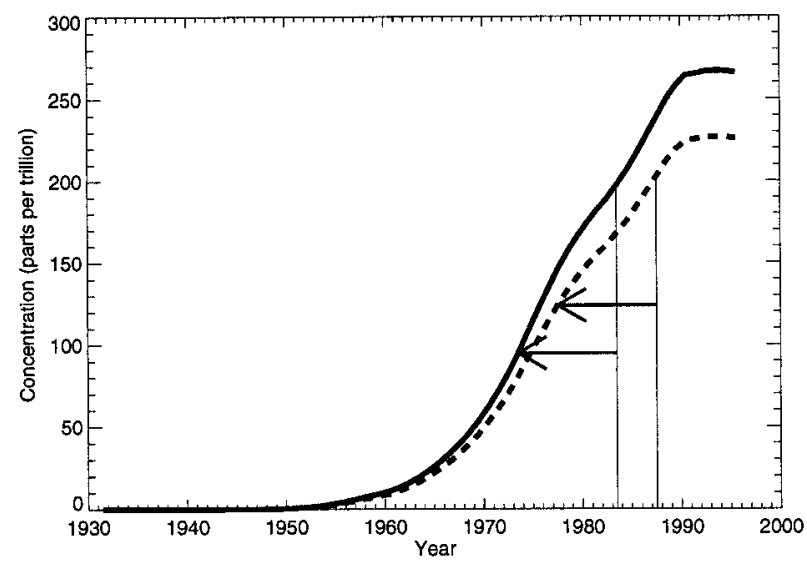

FIG. 6. Historical atmospheric CFC-11 concentration (Northern Hemisphere) (solid) and 85\% level (dashed) from Walker et al. (1996, personal communication). A concentration of CFC-11 in air of 200 ppt may be interpreted as $100 \%$ of the 1983 amount, or $85 \%$ of the 1987 amount. Going back 10 years from each potential ventilation year, along the $100 \%$ curve the concentration goes to $95 \mathrm{ppt}$ in 1973 , and along the $85 \%$ curve the concentration goes to $125 \mathrm{ppt}$ in 1977 . Note the lower saturation scenario maps to higher absolute CFC concentrations because CFC concentrations have been increasing over time. example, if an interior particle is 10 years older than when it entered the model domain, and the water it represents was $85 \%$ saturated at formation (in 1987), then based on $85 \%$ of the atmospheric concentration 10 years before $1987(1987-0 \mathrm{yr}=1987)($ Fig. 6) and the solubility, an interior concentration of $1.28 \mathrm{pmol}$ $\mathrm{kg}^{-1}$ is estimated (Fig. 7). Similarly, based on $100 \%$ of the atmospheric CFC concentration 10 yr before 1983 $(1987-4 \mathrm{yr}=1983)$, an interior concentration of 0.91 pmol kg-1 is estimated (Fig. 7). The concentrations based on the case of $85 \%$ and $0 \mathrm{yr}$ are higher than those in the $100 \%$ and $4-y r$ case because in the former the more recent part of the input function (by $4 \mathrm{yr}$ ) is used when atmospheric CFC concentrations were higher.

A tracer age for midthermocline waters entering from the eastern boundary is similarly calculated. The shallower thermocline waters (above $300 \mathrm{~m}$ ) at the IT are primarily of North Pacific origin, and there is a larger South Pacific contribution with increasing thermocline depth (e.g., Gordon and Fine 1996; Hautala et al. 1996). Based upon August 1989 observations (data courtesy of C. Andrié; Fieux et al. 1994), waters at layer 2 depths were at $50 \%$ saturation, and therefore 12 years old with respect to the contemporary atmosphere. An assumption of $100 \%$ saturation at formation is used for these waters. There is also a front present during both the northeast and southwest monsoons (Fieux et al. 1994, 1996) that separates Indonesian seas from the southern subtropical gyre waters. The more southerly waters have higher CFC-11 concentrations. A latitudinal age variation is 


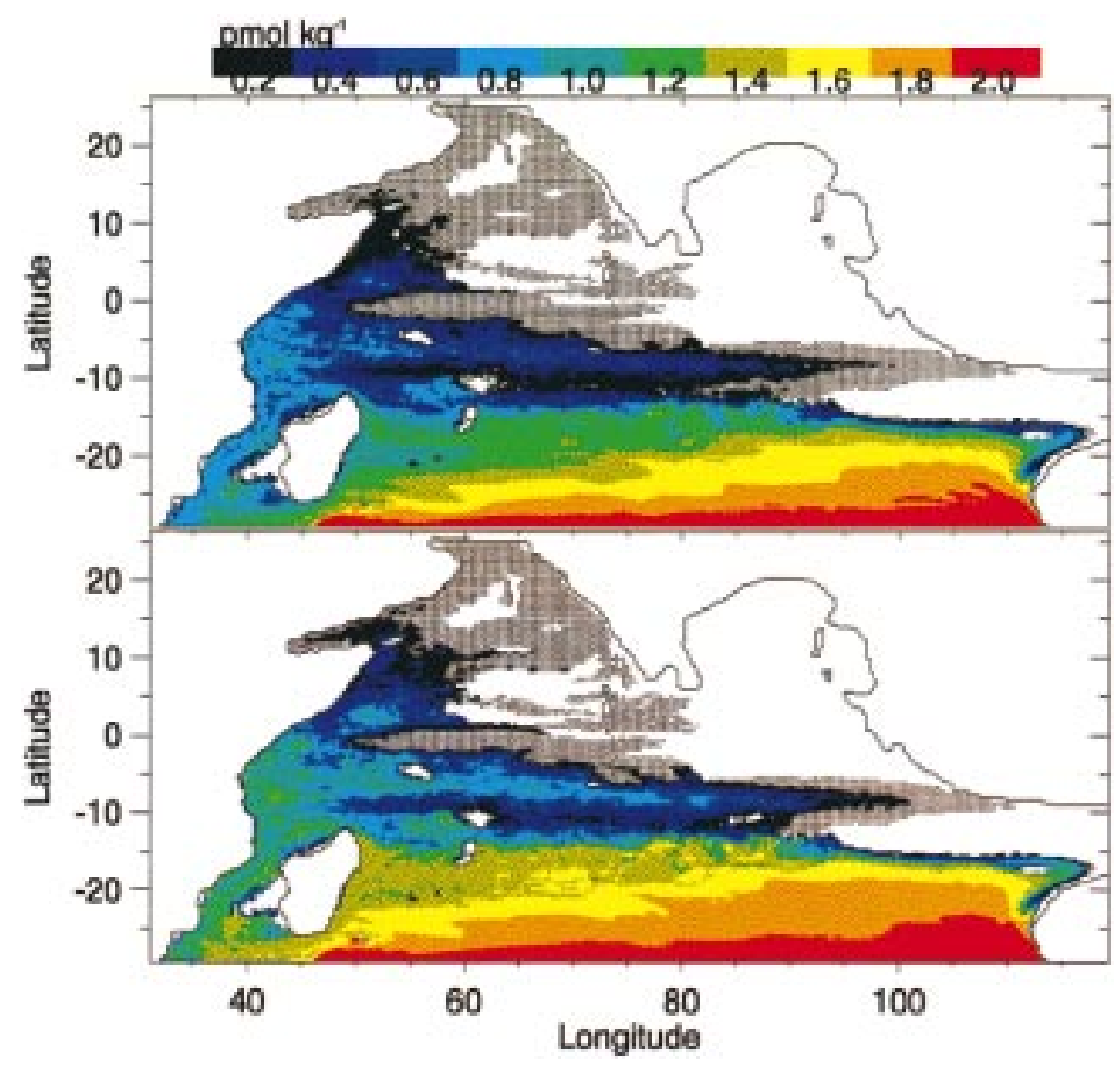

FIG. 7. Model CFC-11 concentrations ( $\mathrm{pmol} \mathrm{kg} \mathrm{kg}^{-1}$ ) in layer 2 for water introduced at the southern boundary in mid-1987 assuming (a) 100\% equilibration at formation, and (b) $85 \%$ equilibration at formation with the contemporary atmosphere. Areas marked with dots indicate water masses have reached those locations, but with negligible CFC concentration.

not introduced because only one year difference in age is indicated.

The CFC-11 modeled contributions from eastern (at $100 \%$ saturation) and southern (at $85 \%$ saturation) sources are combined, giving a distribution illustrated in Fig. 8. The model suggests there is a sharp transition between latitudes $17^{\circ}$ and $13^{\circ} \mathrm{S}$ from the high CFC-11 waters of southern origin and the low CFC-11 waters from the IT. Then, while concentrations are considerably lower equatorward of the subtropical gyre, there are low level CFC-11 concentrations reaching northward along the western boundary into the Arabian Sea. Concentrations greater than $1.5 \mathrm{pmol} \mathrm{kg}^{-1}$ (yellow to red hues) reach as far north as $17^{\circ} \mathrm{S}, 1.0-1.4 \mathrm{pmol} \mathrm{\textrm {kg } ^ { - 1 }}$ (green hues) are present as far north as $13^{\circ} \mathrm{S}$, and concentrations of order $0.5 \mathrm{pmol} \mathrm{\textrm {kg } ^ { - 1 }}$ or less (blue hues) are present northward of $13^{\circ} \mathrm{S}$.

For comparison of model concentrations to CFC observations in the interior Indian Ocean, datasets from $90^{\circ} \mathrm{E}$ (SAGA II) and the Arabian Sea (MASAI II) are used (Fig. 9). These predate the recent WOCE Indian Ocean program measurements, which were not yet available when this work was started. There is a front in the CFC- 11 distribution between $20^{\circ} \mathrm{S}$ and $10^{\circ} \mathrm{S}$.
Southward of $14^{\circ} \mathrm{S}$ CFCs are present to $800 \mathrm{~m}$ or more, but northward to the equator the CFCs all but disappear from waters deeper than $300 \mathrm{~m}$. At model layer 2 depths concentrations are greater than $1.5 \mathrm{pmol} \mathrm{kg}^{-1}$ (yellow to red hues) to the south of the front, and are lower $\left(0.2-1.2 \mathrm{pmol} \mathrm{kg}^{-1}\right)$ and vertically stratified northward. In departure from the observations, the modeled concentrations decrease to near zero north of $7^{\circ} \mathrm{S}$, where there are nonzero values in the observations. Farther west and north, in the Arabian Sea, modeled distributions (Fig. 8) show 0.4 pmol kg-1 CFC-11 just reaching to $10^{\circ} \mathrm{N}$, whereas in observations $0.4 \mathrm{pmol} \mathrm{kg} \mathrm{kg}^{-1} \mathrm{CFC}$ 11 reaches both farther north and farther east along the transect. Also, particle trajectories do not penetrate the center of the northern Arabian Sea gyre, where there are CFCs in detectable amounts. Measurement uncertainties for CFC data are of order $2 \%$ for the Charles Darwin data (Fine 1993) and of order 10\% for the MASAI II data (Prunier 1992).

\section{Forcing experiments}

To quantify the impact of the seasonal cycle on water mass transport, additional trajectory experiments have 


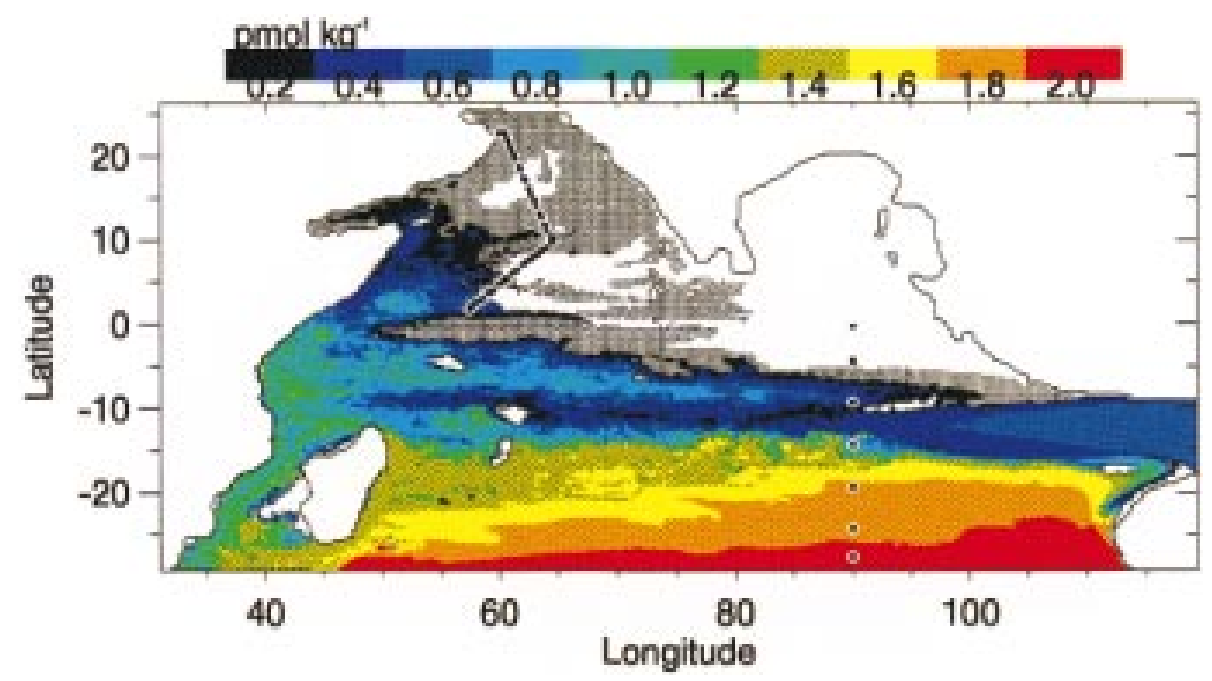

FIG. 8. Model CFC-11 concentrations ( $\mathrm{pmol} \mathrm{kg}^{-1}$ ) in layer 2 from southern boundary waters at $85 \%$ saturation at formation combined with eastern (IT) waters at 100\% saturation at formation. Black dots indicate where observational data (Fig. 9) are located; MASAI II data in the Arabian Sea and SAGA II data along $90^{\circ} \mathrm{E}$.

been carried out using model products that incorporate different degrees of seasonality. In the experiments presented thus far an annual cycle of velocities was used. These velocities were the result of forcing the model with monthly mean climatology (case A). In case B, the same forcing is applied to the model, but the seasonality is removed by using only the annual mean velocities to advect the particles. Therefore, there are no eddies. In case $\mathrm{C}$ the model is driven to a statistically steady state using climatological annual-mean winds. Fluctuations

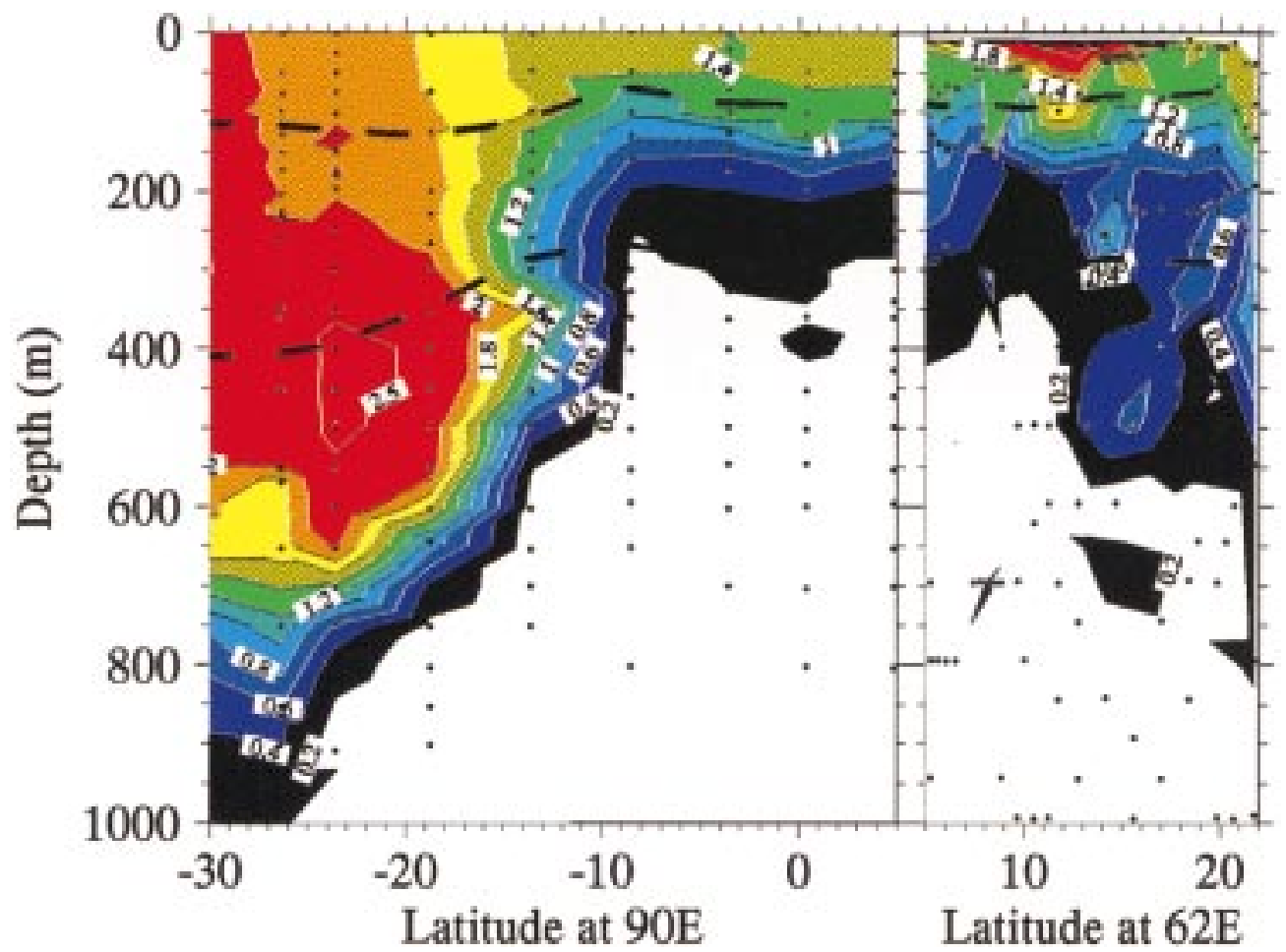

FIG. 9. This depth section of CFC-11 concentrations ( $\mathrm{pmol} \mathrm{kg}^{-1}$ ) is the composite of two datasets. Between latitudes $30^{\circ} \mathrm{S}$ and $5^{\circ} \mathrm{N}$ data are along $90^{\circ} \mathrm{E}$ (SAGA II, June-July 1987, data courtesy R. Gammon). North of latitude $5^{\circ} \mathrm{N}$, data are from $30^{\circ}$ farther west (MASAI II, Jul-Aug 1987). Model layer 2 is between the two dashed horizontal lines. 


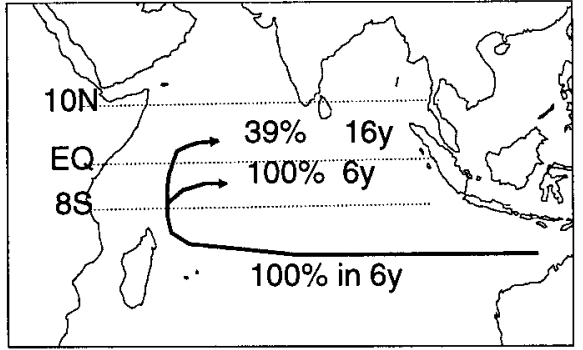

(a) case $B$

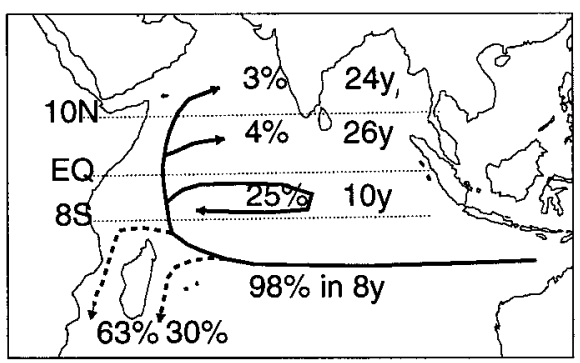

(c) case $\mathrm{C}$

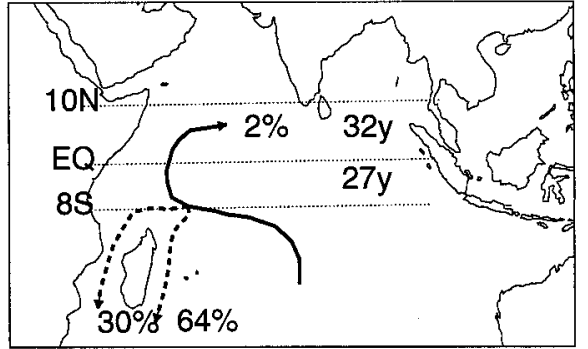

(b) case $\mathrm{B}$

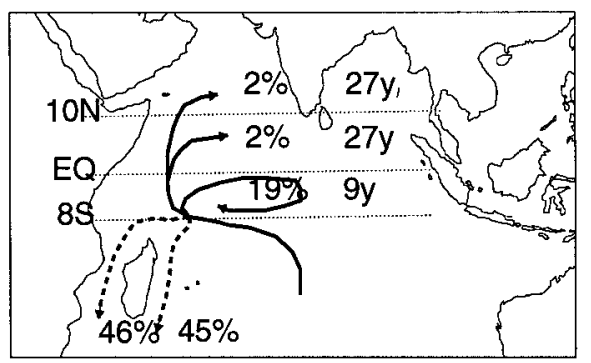

(d) case $\mathrm{C}$

FIG. 10. Summary of 50-yr-long trajectory paths in layer 2 using model velocity products with reduced eddy activity. (a) and (b) Annual average velocities from monthly forced climatology; (c) and (d) an annual cycle of velocities under constant forcing (with mean climatology). The fate of eastern source particles is shown on the left and the fate of southern source particles is shown on the right. The percentage of particles reaching each marked latitude, and the average time taken, is indicated.

about the large-scale mean circulation remain due to instability processes, both barotropic and baroclinic. The variability is at periods shorter than annual; therefore we drive the trajectories repeatedly with a single year of this circulation, with velocities averaged every 6 days. The resulting circulation contains only eddies that are not related to the seasonal cycle because the forcing is steady.

The velocity fields in the forcing experiments require some further discussion because of concerns about the annual cycle applied in each case. In case A, the model was integrated for 50 years using the monthly mean climatological atmospheric fields of Rao et al. (1989). To derive the particle velocities the last year's archived velocity fields were used, repeating year after year for 50 years. Statistics from the last 20 years of this integration confirm that the annual cycle in the model does repeat almost exactly from one year to the next as in Luther and O'Brien (1989). The only year-to-year variability found in the model fields is in the small-scale eddies generated by instability mechanisms in the southwest monsoon Somali Current system and in the equatorial waves excited by these eddies. The amplitude of this variability is very small relative to the mean annual cycle. In case $\mathrm{C}$, the model was driven to a statistically steady state using the constant annual-mean winds from the Rao et al. (1989) climatology. The long-term mean of this case is almost identical to that in case B (annual mean of case A velocities), but at any instant there is energetic small-scale variability about the mean flow field generated by instability mechanisms. The variability in this case is all at periods much shorter than annual, so that repeating one year of model velocities is not seen as a major deficiency. In conclusion, these three cases are considered to adequately represent and contrast the effect of eddy variability about the longterm mean circulation and the effect of the full annual cycle on the transport of particles.

\section{a. Eastern boundary}

The annual-mean velocity field (case B) is clearly dominated by the southwest monsoon (Fig. 10a). All the particles entering at the eastern boundary are carried northward at the western boundary and are retained in the domain after 50 years. Although all the particles cross north of $8^{\circ} \mathrm{S}$, and $39 \%$ go on to cross the equator in comparable times to those in case A, none reach the Arabian Sea. Furthermore, the constant-forced case C (Fig. 10c) is similar to A (Fig. 2a), but fewer particles reach the Arabian Sea (3\% compared to $11 \%$ ) and they take longer (24 yr compared to $18 \mathrm{yr}$ ). 


\section{b. Southern boundary}

The subtropical gyre dominates the transport of particles from the southern boundary. In case B 94\% of the southern origin particles are swept back out of the model domain by the gyre circulation (Fig. 10b). In contrast, $100 \%$ of the particles of eastern origin remain in the model domain (Fig. 10a). Just $2 \%$ of the southern particles are carried to northerly latitudes in case B, compared to $15-20 \%$ in cases A and C. Again, the constant-forced case C (Fig. 10d) has a particle distribution pattern that resembles case A (Fig. 2), but fewer particles reach the Arabian Sea (2\% compared to 4\%). They also take longer to do so (27 yr compared to $17 \mathrm{yr}$ ). However, cases A and B have the same partitioning of particles exiting north and south of Madagascar (1:2) compared with case $C$, where the partitioning is $1: 1$. The reason case $\mathrm{C}$ does not look more like case $\mathrm{A}$ in this regard is curious and suggests that constant forcing does not adequately reproduce all the currents.

\section{Discussion}

The experiments described here are complementary to the particle trajectory experiments presented by Döös (1995) using velocities from the Fine Resolution Antarctic Model (FRAM). Döös confronted similar computational limitations and chose to retain high numbers of trajectories at the expense of time variation of velocity fields in his study of interocean water mass exchange. The horizontal resolution in FRAM $\left(1 / 4^{\circ} \times 12^{\circ}\right)$ is comparable to the horizontal resolution of the archived fields from the Indian Ocean circulation model $\left(1 / 3^{\circ} \times 1 / 3^{\circ}\right)$, whereas the 32 vertical layers in FRAM allow quantitative volume fluxes to be inferred from the trajectory paths. The emphasis in this study, on meridional transports in a region of large seasonal changes, required more computational effort to be spent on the time resolution of velocity fields at the expense of higher numbers of trajectories and vertical layers.

The western boundary's importance as the main meridional spreading pathway of thermocline waters is apparent in the Lagrangian experiments. On the other hand, the equatorward boundary of the subtropical gyre at $15^{\circ} \mathrm{S}$, a prominent feature in hydrographic properties (Wyrtki 1971; Conkright et al. 1994), appears to be a barrier to northward exchange in the interior. The mean flow and eddies both contribute to the cross-equatorial transport. The highest percentage of particles crossing the equator are in the mean-flow case B and were introduced along the eastern boundary. Schott et al. (1990) also estimate a large contribution of the mean flow to the cross-equatorial transport, based on measurements limited to the Somali Current region during the northeast monsoon. Nevertheless, the trajectory experiments also show that although the mean flow is locally important for cross-equatorial transport along the western boundary, eddies are needed to allow subtropical particles to escape the gyre and join the mean northward flow. When eddies are present (cases $\mathrm{A}$ and $\mathrm{C}$ ), higher percentages of southern boundary particles escape the gyre and reach farther northward of $8^{\circ} \mathrm{S}$ than in case $\mathrm{B}$, which has no eddies. The percentages are $14 \%, 19 \%$, and $2 \%$ for cases $\mathrm{A}, \mathrm{C}$, and $\mathrm{B}$, respectively. Comparable percentages of particles then cross the equator in each case $(2 \%-5 \%)$, indicating that the mean flow is the dominant mechanism for cross-equatorial transport right at the equator.

Particles originating from the IT reach the western boundary at latitudes influenced by the Somali Current system and are, therefore, less dependent on eddies to reach and cross the equator. After crossing the equator it is only in the presence of time-varying circulation that any particles reach into the northern Arabian Sea, from either the southern or the eastern boundary. The eddies present in the monthly forced velocity fields appear to be particularly effective for transporting particles northward from the equatorial region. In case A a larger percentage of particles are transported northward of $10^{\circ} \mathrm{N}$ on shorter timescales than in case C: $11 \%$ in 18 yr compared to $3 \%$ in $24 \mathrm{yr}$ from the eastern boundary, and $4 \%$ in $17 \mathrm{yr}$ compared to $2 \%$ in $27 \mathrm{yr}$ from the southern boundary (Figs. 2 and 10). Thus, there is a net transport of thermocline particles along the western boundary into the northern Indian Ocean on timescales of less than two decades, which is strongly dependent on different forcing at different latitudes.

A significant percentage of particles do not reach the northern Indian Ocean, rather they remain in the equatorial region. These appear to flow east/west in three zonal bands (Fig. 4): north, south, and on the equator. The particles in the northern and equatorward bands only reach eastward to the central ocean. The southern band is clearly aligned with the seasonal SECC and it reaches farthest eastward. The northern band is where the westward flowing southwest monsoon current is present during part of the year and the eastward flowing North Equatorial Current at other times. The weaker band on the equator coincides with the Equatorial Undercurrent, which disappears during the southwest monsoon. The overall impression is that, even after 20 years, particles introduced along both open boundaries remain in the basin and alternately flow eastward and westward with the seasonally reversing currents. It is likely that the seasonally reversing equatorial currents are an efficient blender of water masses.

The distinguishing hydrographic property of IT water is its low salinity $(S<34.8 \mathrm{psu})$. According to YT93, IT water can be identified to $70^{\circ} \mathrm{E}$. In their model IT does not directly exit the Indian Ocean, rather, some goes north and some south along the western boundary. Particles from the IT are also seen to do this (section 3a). IT water mixes with SICW-producing equatorial water (Sverdrup et al. 1942). Based on the percentages of model particles (Fig. 2) reaching the equatorial region from each boundary, equatorial water appears to be a mixture with a ratio three parts SICW to one part IT. 
This is in agreement with YT93, who present water mass composition for the thermocline over the entire Indian Ocean. In the 10 degree band north of the equator in the western portion of the basin, YT93 show about equal contributions of Red Sea Water and IT, to three parts SICW and seven parts aged SICW. In a seasonal analysis, You (1997) finds these waters contribute more to the circulation and ventilation in the western boundary region during the summer monsoon. Recently, Morales et al. (1996) discuss the confluence of five water masses in the upper $300 \mathrm{~m}$, and their observations suggest water mass composition in the western tropical Indian Ocean is subject to rapid temporal variability. They noted distinct water mass patches moving through the sampling region on the timescale of days.

Model-observational comparisons point to several limitations in the model. The model may be underestimating eddy mixing. The interior of the Arabian Sea and south Indian subtropical gyres remain relatively particle free, whereas there are measurable CFCs. That no IT water subsequently mixes into the southern gyre differs from the tritium distribution of Fine (1985). The velocities used to advect the particles are 6-day averages and small-scale variability is lost by this averaging process. It might be reasonable to add noise to the velocities to represent the small-scale mixing that may be important in the ventilation of the interior of the gyres. This has been shown to be the case in models-in western boundary regimes of subtropical gyres (e.g., Thiele and Sarmiento 1990).

There is a problem regarding exchange in the model with the Bay of Bengal. The model shows no particles reaching the Bay of Bengal thermocline on decadal timescales. While YT93 also suggest that thermocline water in the Bay of Bengal can only be very old SICW; they also note the contribution of northward-spreading IT thermocline waters along the eastern ocean boundary. CFC observations (Howell et al. 1997) indicate ventilation times of less than $40 \mathrm{yr}$ for waters above $500 \mathrm{~m}$ in this region. Sources of water for the Bay of Bengal are not well understood. The IT may contribute "younger" water to the Bay of Bengal and, since the model underestimates the annual transport range, this may affect the distributions. To resolve this issue it is probably necessary to use a model that resolves known seasonal currents in the eastern Indian Ocean.

A limitation is related to an inability in the model to allow particles that leave the model domain to reenter. This raises questions about the trajectory results from the southern boundary since this boundary cuts through the middle of a recirculating gyre. In essence, there is no dilution of particle concentrations with any recirculating boundary waters or waters in the interior of the model domain. The trajectory experiments simply answer the question in a relative sense; that is, what is the average time and pathway that particles reaching northern destinations take, starting from the model southern boundary? Particles that exit the domain, whether or not they might recirculate, are explicitly excluded. The CFC concentrations at the southern boundary give a measure of the blended tracer age of the waters there, which is then added to the particle ages calculated from the trajectories. This is further complicated by interpretations of pCFC age (Doney et al. 1997). In future work it would be interesting to use the CFCs to calculate the age composition of the blended waters, using a model with full gyre circulation.

Another modeling limitation is related to vertical exchange between layers. There is intense upwelling in the Arabian Sea during the summer monsoon. A strong meridional circulation is also suggested from heat transport considerations (Robbins and Toole 1997; Lee and Marotzke 1997). Based on limited observations, the model/tracer comparisons at model layer 2 depths suggest that replenishment by vertical mixing with the layer above is more important in the Arabian Sea than in the region at $90^{\circ} \mathrm{E}$. Results of mixed layer $\mathrm{CFC}$ modeling (Haines et al. 1997) showed mixed layer CFC concentrations are insensitive to dilution with thermocline waters.

\section{Conclusions}

Model experiments using Lagrangian particles and comparisons with tracer data are used to quantify meridional pathways and timescales of spreading of Indian Ocean midthermocline waters under different forcing conditions. Comparisons with tracer observations also indicate some limitations in the model.

Trajectory experiments show that transport of thermocline water into the northern Arabian Sea occurs along the western boundary. The experiments confirm that these waters reach the Arabian Sea on timescales of two decades (Prunier 1992) from either the southern or eastern open boundaries. Both the rate of transport and tracer concentration at oceanic boundaries need to be considered when evaluating ventilation sources. For the latter reason the contribution from the southern boundary is more important.

A large percentage of particles entering from both boundaries remain in the equatorial region coincident with the zonal currents. In the equatorial region the seasonally reversing currents appear to act as an effective water mass blender creating Equatorial Water. In agreement with YT93, equatorial water is partially comprised of SICW and IT in the ratio 3:1. Along a northsouth section at $90^{\circ} \mathrm{E}$ the model trace concentrations and CFC-11 observations are similar at model layer 2 depths. Both illustrate the sharp front between south Indian subtropical gyre waters and IT waters.

Comparison of the model results with observations highlight some limitations in the circulation model. The annual cycle of IT transports underestimates the annual range found in observations. Mass transport from the IT region to the Bay of Bengal on timescales $<50 \mathrm{yr}$ does not occur in the model, perhaps because locally 
important forcing due to salinity and the Pacific Ocean are not parametrized in the model. Another limitation is that velocity averaging may underestimate horizontal mixing, and as a consequence the interior of gyres remain relatively void of particles.

A key issue involves the pathways, the timescale, and processes involved in the cross-equatorial flux of heat and other properties into the northern Indian Ocean. Experiments showed that 1) transport in eddies is necessary in order for water to escape the southern subtropical gyre; 2) the mean flow dominates the local cross-equatorial transport, in agreement with observations (Schott et al. 1990); 3) then, for subsequent transport into the northern Indian Ocean, eddies are necessary. Eddies produced by atmospheric forcing that retain seasonal variations appear to be most effective. The experiments suggest that particle transport to the northern Indian Ocean, and presumably also transport of mass and heat, would not be well represented by a simple parameterization of eddy mixing (diffusivity) about the mean circulation. Any synthesis model must include the full annual cycle. The impact of the eddy transport on the heat flux is quantified in a companion paper ( $\mathrm{Ji}$ and Luther 1998, manuscript submitted to J. Geophys. Res.).

Acknowledgments. The authors acknowledge support by National Science Foundation Grants OCE-9314781, OCE-9316003, OCE-9529847, OCE-9413222, and OCE-9216984. Development of the numerical circulation model was funded in part by the Office of Naval Research and the National Aeronautics and Space Administration. We thank Jay McCreary for assistance in model development, James O'Brien for suggesting the Lagrangian experiments, Chantal Andrié and Richard Gammon for making their CFC data available, and anonymous reviewers for their constructive comments and suggestions.

\section{REFERENCES}

Bruce, J. G., 1973: Large-scale variations of the Somali Current during the southwest monsoon, 1970. Deep-Sea Res., 20, 837-846.

Camerlengo, A. L., and J. J. O'Brien, 1980: Open boundary conditions in rotating fluids. J. Comput. Phys., 35, 12-35.

Conkright, M. E., S. Levitus, T. P. Boyer, D. M. Bartolacci, and M. E. Luther, 1994: Atlas of the Northern Indian Ocean. NOM Tech. Rep. NOAA and University of South Florida, 158 pp. [Available from Dept. of Marine Science, University of South Florida, 140 Seventh Avenue South, St. Petersburg, FL 33701.]

Doney, S., and J. L. Bullister, 1992: A chlorofluorocarbon section in the eastern North Atlantic. Deep-Sea Res., Part A, 39, 18571883

— W. W. Jenkins, and J. L. Bullister, 1997: A comparison of ocean tracer dating techniques on a meridional section in the eastern North Atlantic. Deep-Sea Res., 44, 603.

Döös, K., 1995: Interocean exchange of water masses. J. Geophys. Res., 100, 13 499-13 514.

England, M., 1995: Using chlorofluorocarbons to assess ocean climate models. Geophys. Res. Lett., 22, 3051-3054.

, V. C. Garcon, and J.-F. Minster, 1994: Chlorofluorocarbon uptake in a World Ocean model. Part 1: Sensitivity to the surface gas forcing. J. Geophys. Res., 99, 25 215-25 233.
Fieux, M., C. Andrié, P. Delecluse, A. G. Ilahude, A. Kartavtseff, F. Mantisi, R. Molcard, and J. Swallow, 1994: Measurements within the Pacific-Indian Oceans throughflow region: Preliminary results of the JADE cruise. Deep-Sea Res., 41, 89-112.

- - - E. Charriaud, A. G. Ilahude, A. Kartavtseff, F. Mantisi, N. Metzl, R. Molcard, and J. C. Swallow, 1996: Hydrological and chlorofluoromethane measurements of the Indonesian throughflow entering the Indian Ocean. J. Geophys. Res., 101, $12433-12454$.

Figueroa, H. A., 1994: Eddy resolution versus eddy diffusion in a double gyre GCM. Part II: Mixing of passive tracers. J. Phys. Oceanogr., 24, 387-402.

Findlay, A. G., 1866: A Directory for the Navigation of the Indian Ocean. Richard Holmes Laurie.

Fine, R. A., 1985: Direct evidence using tritium data for throughflow from the Pacific into the Indian Ocean. Nature, 315, 478-480. , 1993: Circulation of Antarctic Intermediate Water in the South Indian Ocean. Deep-Sea Res., 40, 2021-2042.

_ - M. A. Warner, and R. F. Weiss, 1988: Water mass modification at the Agulhas Retroflection: Chlorofluoromethane studies. Deep-Sea Res., 35, 311-332.

Gent, P. R., K. O'Neill, and M. A. Cane, 1983: A model of the semiannual oscillation in the equatorial Indian Ocean. J. Phys. Oceanogr., 13, 2148-2160.

Gill, A. E., 1982: Atmosphere-Ocean Dynamics. Academic Press, $662 \mathrm{pp}$.

Gordon, A., and R. Fine, 1996: Pathways of water between the Pacific and Indian Oceans in the Indonesian seas. Nature, 379, 146149.

Haines, M. A., M. E. Luther, and R. A. Fine, 1997: Model-validated parametrization for air-sea gas transfer in the North Indian Ocean. Geophys. Res. Lett., 24, 2545-2548.

Hautala, S. L., J. L. Reid, and N. Bray, 1996: The distribution and mixing of Pacific water masses in the Indonesian Seas. J. Geophys. Res., 101, 12 375-12 390.

Howell, E. A., S. C. Doney, R. A. Fine, and D. B. Olson, 1997: Geochemical estimates of denitrification in the Arabian Sea and the Bay of Bengal during WOCE. Geophys. Res. Lett., 24, 25492552.

Jensen, T., 1991: Modeling the seasonal undercurrents in the Somali Current system. J. Geophys. Res., 96, 22 151-22 168.

_ 1993: Equatorial variability and resonance in a wind-driven Indian Ocean model. J. Geophys. Res., 98, 22 533-22 552.

Knox, R. A., 1987: The Indian Ocean: Interaction with the monsoon. Monsoons, J. S. Fein and P. S. Stephens, Eds., John Wiley and Sons, 365-397.

Lee, T., and J. Marotzke, 1997: Inferring meridional mass and heat transports of the Indian Ocean by fitting a general circulation model to climatological data. J. Geophys. Res., 102, 10 58510602 .

Levitus, S., 1982: Climatological Atlas of the World Ocean. NOAA Prof. Paper No. 13, U.S. Govt. Printing Office, Washington, DC, $173 \mathrm{pp}$.

Luther, M. E., 1999: Interannual variability in the Somali Current, 1954-1976. Nonlinear Analysis: Real World Applications, Vol. 35, Elsevier Science, 59-83.

- , and J. J. O'Brien, 1985: A model of the seasonal circulation in the Arabian Sea forced by observed winds. Progress in Oceanography, Vol. 14, Pergamon, 353-385.

— Mesoscale/Synoptic Coherent Structures in Geophysical Turbulence, J. C. Nihoul and B. M. Jamart, Eds., Elsevier Oceanogr. Ser., Vol. 50, Elsevier Science, 373-386.

McCartney, M. S., 1982: The subtropical recirculation of mode waters. J. Mar. Res., 40, 424-464.

Meyers, G., R. J. Bailey, and A. P. Worby, 1995: Geostrophic transport of Indonesian Throughflow. Deep-Sea Res., Part I, 42, 11631174.

Morales, R. A., E. D. Barton, and K. J. Heywood, 1996: Variability 
of water masses in the western Indian Ocean. J. Geophys. Res., 101 (C6), 14 027-14 038.

Press, W. H., S. A. Teukolsky, W. T. Vetterling, and B. P. Flannery, 1992: Numerical Recipes in Fortran: The Art of Scientific Computing. Cambridge University Press, 963 pp.

Prunier, K. T., 1992: The spreading, mixing and ventilation of thermocline and intermediate waters in the Arabian Sea. M. S. thesis, Rosenstiel School of Marine and Atmospheric Science, University of Miami.

Quadfasel, D. R., and G. R. Cresswell, 1992: A note on the seasonal variability of the South Java Current. J. Geophys. Res., 97, 36853688 .

Rao, R. R., R. I. Molinari, and J. F. Festa, 1989: Evolution of the climatological near-surface thermal structure of the tropical Indian Ocean. Part I: Description of monthly mean mixed layer depth, and sea surface temperature, surface current, and surface meteorological fields. J. Geophys. Res., 94, 10 801-10 815.

Rhein, M., 1991: Ventilation rates of the Greenland and Norwegian Seas derived from distributions of CFMs F11 and F12. DeepSea Res., Part A, 38, 485-503.

Robbins, P. E., and J. M. Toole, 1997: The dissolved silica budget as a constraint on the meridional overturning circulation of the Indian Ocean. Deep-Sea Res., Part A, 44, 879-906.

Robitaille, D. Y., and A. J. Weaver, 1995: Validation of sub-gridscale mixing schemes using CFCs in a global ocean model. Geophys. Res. Lett., 22, 2917-2920.

Schott, F., J. C. Swallow, and M. Fieux, 1990: The Somali Current at the equator: Annual cycle of currents and transports in the upper $1000 \mathrm{~m}$ and connection to neighboring latitudes. DeepSea Res., 37, 1825-1848.

Semtner, A. J., Jr., and R. M. Chervin, 1992: Ocean general circulation from a global eddy resolving model. J. Geophys. Res., 97, 54935550 .

Sprintall, J., and M. Tomczak, 1993: On the formation of Central Water and thermocline ventilation in the Southern Hemisphere. Deep-Sea Res., 40, 827-848.
Sverdrup, H. U., M. W. Johnson, and R. H. Fleming, 1942: The Oceans, Their Physics, Chemistry, and General Biology. Prentice-Hall, $1087 \mathrm{pp}$.

Swallow, J., 1984: Some aspects of the physical oceanography of the Indian Ocean. Deep-Sea Res., 31, 639-650.

- - and M. Fieux, 1982: Historical evidence for two gyres in the Somali Current system. J. Mar. Res., 40 (Suppl.), 747-755.

,-- , and F. Schott, 1988: The boundary currents east and north of Madagascar. Part I: Geostrophic currents and transports. $J$. Geophys. Res., 93, 4951-4962.

Theile, G., and J. L. Sarmiento, 1990: Tracer dating and ocean ventilation. J. Geophys. Res., 95, 9377-9391.

Toole, J. M., and B. A. Warren, 1993: A hydrographic section across the subtropical south Indian Ocean. Deep-Sea Res., 40, 19732019.

Wallace, D. W. R., and J. R. N. Lazier, 1988: Anthropogenic chlorofluoromethanes in newly formed Labrador Sea Water. Nature, 332, 61-63.

Warner, M. J., and R. F. Weiss, 1985: Solubilities of chlorofluorocarbons 11 and 12 in water and seawater. Deep-Sea Res., 32, $1485-1497$.

Warren, B. A., H. Stommel, and J. C. Swallow, 1966: Water masses and patterns of flow in the Somali Basin during the southwest monsoon of 1964. Deep-Sea Res., 13, 825-860.

Woodberry, K. E., M. E. Luther, and J. J. O'Brien, 1989: The winddriven seasonal circulation in the southern tropical Indian Ocean. J. Geophys. Res., 94, 17 985-18 002.

Wyrtki, K., 1971: Oceanographic Atlas of the International Indian Ocean Expedition. Balkema, 531 pp.

You, Y., 1997: Seasonal variations of thermocline circulation and ventilation in the Indian Ocean. J. Geophys. Res., 102, 10 39110422 .

- and M. Tomczak, 1993: Thermocline circulation and ventilation in the Indian Ocean derived from water mass analysis. DeepSea Res., 40, 13-56. 